\title{
Perception of the World Climate Summit in Katowice (COP24) by the Millennial Generation
}

\author{
Małgorzata Kieżel, Paweł Piotrowski, Joanna Wiechoczek \\ University of Economics in Katowicel Department of Marketing Management and Tourism
}

\begin{abstract}
COP24 is the informal name for the 24th Conference of the Parties to the United Nations Framework Convention on Climate Change (UNFCCC). The COP takes decisions which are necessary to ensure the effective implementation of the provisions of the Convention. COP24 conference took place from 2-16 December 2018 in Katowice, i.e. in the main city of The Upper Silesian Industrial Region (one of the largest industrial areas in Europe) located in southern Poland. This study investigates the perception of the World Climate Summit organized in a city such as Katowice by the Millennial generation. The study assumes the hypothesis that in the opinion of the young generation: Katowice has improved its image by organizing international climate conference; the conference will positively affect the number of tourists visiting Katowice in the future and the city should organize more similar international events. But on the other hand the Millennials are critical about the positive impact of the COP24 findings on global climate protection and increased environmental awareness of societies. A critical analysis of the literature on the subject of the World Climate Summit and United Nations Framework Convention on Climate Change based on books and journals, as well as Internet sources about the COP24 is used in the study. Documentary methods are applied, and the results of quantitative research based on survey research methodology are presented. The article consist of four parts. The idea, goals and assumptions of the World Climate Summits, as well as the specifics of the Millennial generation's behaviours are presented in the first part of body of paper. Then, the research methods and respondents characteristics are presented. The main part of the article shows the results of the survey. They show how the Millennial generation perceives such an event as the COP24 in Katowice (including its positives and negatives). The article ends with discussion and conclusions.
\end{abstract}

Keywords: Climate Change; Ecology, International Climate Summit; Millenials; Sustainable Development 